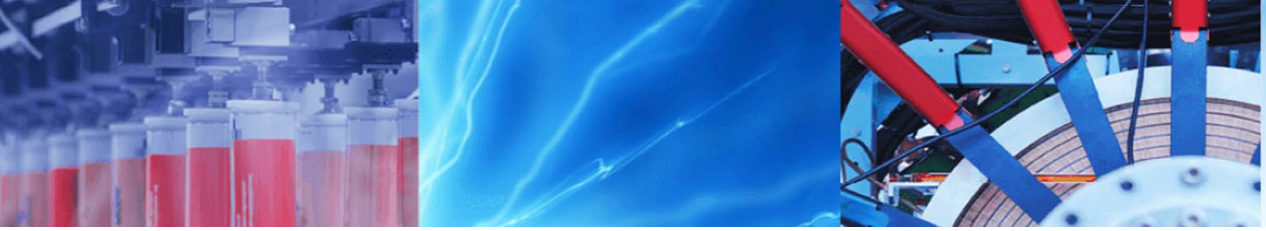

Short Communication

\title{
Removal of chlorinated pesticide contamination by soil washing with sole water
}

\author{
Marco Tagliabue $^{1}$ (D) Manuela Grande $^{2} \cdot$ Sara Perucchini $^{2} \cdot$ Michela Bellettato $^{3} \cdot$ Erica Montanari $^{3}$
}

Received: 7 January 2020 / Accepted: 27 February 2020 / Published online: 5 March 2020

(c) Springer Nature Switzerland AG 2020

\begin{abstract}
Chlorinated pesticide soil contamination still affects large territories due to past extensive use, poor solubility in water and scarce biodegradability of these agro-chemicals. In particular, this is noticeable for dichloro-diphenyl-trichloroethanes and their derivatives, globally referred as DDX contaminants. Presently, containment or immobilisation is a dominant approach to limit contamination, and remediation has been tried mainly at laboratory scale with contradictory results. Soil washing has been reported as a possible remediation treatment, although environmental effects of employed synthetic co-solvents or surfactants remain unclear. A soil washing treatment with sole water has been set up at laboratory scale, obtaining promising results on a contaminated soil with DDX level of $5050 \mathrm{mg} / \mathrm{kg}$.
\end{abstract}

Keywords Attrition ·DDT · Clay · Remediation · Silt · Soil

\section{Introduction}

Production and use of chlorinated pesticides have been favoured by their effectiveness in limiting the spread of harmful insects. On the other hand, the poor solubility in water and scarce biodegradability of these agro-chemicals have caused their accumulation in soil of sites involved in chemical or agricultural activities. Relevant environmental [1, 2] and human health issues [3] still affect large territories. In particular, this is noticeable for dichlorodiphenyl-trichloroethanes (DDTs) and their derivatives dichloro-diphenyl-dichloroethanes (DDDs), dichlorodiphenyl-dichloroethenes (DDEs) globally referred as DDX contaminants. Their persistence has been reported after decades from their ban from the market [4]. Different approaches have been proposed in presence of chlorinated pesticide-contaminated soil including containment, immobilisation, desorption, flushing, chemical or biological degradation $[5,6]$. Effectiveness of most of them has been reported only at laboratory scale while containment or immobilisation is extensively practised [6]. Soil washing has drawn attention for its successful implementation in presence of organic [7] and inorganic [8] contaminants even mixed together [9]. Its limited environmental impact in terms of greenhouse gas emissions in comparison with other soil remediation treatments has been pointed out as additional benefit [10]. In general, it entails operations of excavation, separation of coarse fraction, attrition scrubbing, washing, separation of remediated fractions from contaminated fractions and treatment or disposal of the latter ones as wastes [11]. In particular, attrition scrubbing is an operation derived from mining industry, consisting in an energetic stirring of soil with a proper liquid, run by machines with helical impellers or opposite blades. Friction produced among soil particles results in mobilisation of contaminants adhered to particle surface and disaggregation of particle agglomerates. In practice, attrition scrubbing promotes concentration of contaminants in

\footnotetext{
$\triangle$ Marco Tagliabue, marco.tagliabue@eni.com | ${ }^{1}$ Renewable Energy and Environmental Laboratories, Eni S.p.A., San Donato Milanese, Italy. ${ }^{2}$ Renewable Energy and Environmental Laboratories, Eni S.p.A., Novara, Italy. ${ }^{3}$ Downstream Process Technology Laboratories, Eni S.p.A., San Donato Milanese, Italy.
} 
liquid [12] or in silt [13] improving soil washing effectiveness. In general, soil particle size distribution is not affected although additional silt can be produced by comminution in case of attrition operated in presence of added abrasive powders [14]. Soil washing optimisation is mainly empirical depending on several microscopic phenomena involved (e.g., mobilisation, disaggregation, comminution, sorption, dissolution), contaminated soil and apparatus peculiarities [15]. In particular, the literature on chlorinated pesticide-contaminated soils is scarce although careful extrapolation can be done considering other organic contaminants. In general, synthetic co-solvents or surfactants have to be employed $[5,6]$. The latter ones can affect soil microbial population acting as poisons or nutrients. Furthermore, information on their regeneration when exhausted is lacking, pointing to the risk of additional dangerous waste production [6]. According to that, great environmental benefits could derive from setting up soil washing treatments based on sole water. Promising results on DDX contaminated soil obtained at Eni S.p.A. laboratories within a remediation project managed by Eni Rewind S.p.A. (former Syndial S.p.A., Eni S.p.A. subsidiary for environmental activity) are reported [16].

\section{Material and methods}

Raw soil was sampled from a disused Italian industrial site previously devoted to agro-chemical production and storage [1]. It was air dried for $8 \mathrm{~h}$ at room temperature and atmospheric pressure till weight invariance and screened to isolate the fraction of particles with size less than $2 \mathrm{~mm}$, referred as screened soil. The latter one was $99 \mathrm{wt} \%$ of the raw soil. Moisture loss was about $10 \mathrm{wt} \%$. For balance purposes, an aliquot was further screened to isolate the fractions of particles with size larger and smaller than $0.63 \mu \mathrm{m}$, respectively, referred as sand and silt. The latter one was about $20 \mathrm{wt} \%$. of the screened soil. Then, $3 \mathrm{~kg}$ of screened soil were placed in an Erweka PRS ${ }^{\mathrm{TM}}$ planetary stirrer (holding capacity of $5 \mathrm{dm}^{3}$ ) assembled on an Erweka AR403 ${ }^{\text {TM }}$ apparatus and $900 \mathrm{~g}$ of tap water were added $(\mathrm{pH}$ of 7.0 measured by Macherey-Nagel pH-Fix $0-14 \mathrm{PT}^{\mathrm{TM}}$ strips, electrical conductivity of $422 \mu \mathrm{S} / \mathrm{cm}$ measured by a Hach sensION ${ }^{\mathrm{TM}}$ instrument equipped with a Hach $50-70^{\mathrm{Tm}}$ electrode). The mixture was stirred for $120 \mathrm{~min}$ at $90 \mathrm{~min}^{-1}$ obtaining a dense paste with no appreciable $\mathrm{pH}$ variation. It is noticeable, that solid-to-liquid ratio was within the range recommended in the literature on attrition scrubbing while rotation speed was lower [17]. These mild conditions were adopted to avoid production of further silt, emulsion and heating due to friction. Afterwards, $600 \mathrm{~g}$ of the aforementioned paste was diluted with tap water up to a total volume of $900 \mathrm{~cm}^{3}$. The diluted paste was stirred for $30 \mathrm{~min}$ at room temperature in a Velp Scientifica Rotax $6.8^{\mathrm{TM}}$ rotary stirrer at $5 \mathrm{~min}^{-1}$ and then kept without stirring for further $30 \mathrm{~min}$. Afterwards, it was filtered on a Carlo Erba FPE204250 ${ }^{\mathrm{TM}}$ buchner filter equipped with a polyethersulphone membrane with porosity of $0.22 \mu \mathrm{m}$. Recovered soil was air dried for $8 \mathrm{~h}$ at room temperature and atmospheric pressure till weight invariance and underwent to screening to isolate the silt. The latter one was still about $20 \mathrm{wt} \%$ of the recovered soil, pointing to unappreciable particle comminution. All screening operations were run by a Retsch $\mathrm{AS} 200^{\mathrm{TM}}$ apparatus equipped with Endecotts stainless-steel screens.

DDX level quantification on solids and liquids was carried out using gas chromatography coupled with mass spectrometry (GC-MS) according to standard methods, respectively, EPA 3545A [18] and EPA 8270D [19] by an external laboratory.

Further physical-chemical characterisation was carried out on solids.

Structural analysis was performed by $\mathrm{x}$-ray powder diffraction (PXRD). A PANalytical Empyrean ${ }^{\text {TM }}$ diffractometer equipped with a real-time multiple strip (RTMS) PIXcel 3D ${ }^{\text {TM }}$ detector was employed. Data were collected in the angular range from $3^{\circ}$ to $70^{\circ}$ with $0.03^{\circ} 2 \theta$ step and $10 \mathrm{~s} / \mathrm{step}$ accumulation time. The CuKa radiation with wavelength of 1.54178 A was used. Powdered samples were loaded into a boro-silicate glass capillary which was spun during data collection to minimise preferred orientation phenomena. Qualitative analysis was carried out with a search-match method developed in the PANalytical X'Pert HighScore ${ }^{\text {TM }}$ software package.

Microscopic observations were performed using a Reichet Jung Polyvar MET ${ }^{\mathrm{TM}}$ microscope in reflection mode. Samples were embedded into epoxy resin and polished with silicon carbide papers. Diamond paste was used for final polishing.

Particle size distribution was evaluated by static light scattering (SLS) using a Coulter Beckman LS $13320^{\mathrm{Tm}}$ analyser equipped with an aqueous liquid module Coulter Beckman $\mathrm{ALM}^{\mathrm{TM}}$. Solids were suspended in a $1 \mathrm{wt} \%$ ethylene glycol aqueous solution (Carlo Erba Reagents RPE ${ }^{\mathrm{TM}}$ grade). Data collection was replicated six times in order to smooth the noise due to presence of clay agglomerates.

\section{Results and discussion}

Whole soil washing treatment was replicated on two different raw soil lots from the same site and average results have been reported in this study.

Silt has been noticed as the most contaminated fraction of screened soil. In fact, DDX level in screened soil has been $5050 \mathrm{mg} / \mathrm{kg}$ while in silt has been $11,300 \mathrm{mg} /$ 
$\mathrm{kg}$, corresponding to about $45 \mathrm{wt} \%$ of raw soil DDX contaminants.

After soil washing treatment, DDX level in silts has increased to $24,950 \mathrm{mg} / \mathrm{kg}$, corresponding to about $99 \mathrm{wt} \%$ of raw soil DDX contaminants. In other words, large part of DDX contaminants has been concentrated in a limited fraction of raw soil. Furthermore, DDX level in tap water has been less than $1.0 \mu \mathrm{g} / \mathrm{dm}^{3}$, according to DDX poor solubility in water.

Structural analysis has pointed to quartz and feldspar (albite) as the main phases of screened soil with kaersutite and clay minerals (muscovite and chamosite) as minor phases (Fig. 1). Virtually identical mineralogical composition has been noticed in recovered soil and silt after soil washing treatment, with the latter one slightly enriched in clays. It agrees with marked affinity among chlorinated pesticides and clay sorbents referred in the literature [20].

Microscopic observations were carried out on screened soil before the attrition and on the two different fractions obtained after the mechanical treatment. Microscopic observations of screened soil before soil washing have shown particles with irregular shape and different sizes, ranging from few up to $100 \mu \mathrm{m}$ (Fig. 2a). After soil washing, particles with larger size have been still present in sand (Fig. 2b) while fines have been removed and concentrated in silt (Fig. 2c). Particles have retained their initial irregular shape with sharp edges and corners, confirming unappreciable comminution. In other words, no further silt has been produced, minimising dangerous wastes to treatment or disposal.

Particle size evaluation basically agrees with these evidences pointing to average particle sizes of about $129 \mu \mathrm{m}$, $43 \mu \mathrm{m}$ and $131 \mu \mathrm{m}$, respectively, on recovered soil, silt and sand.

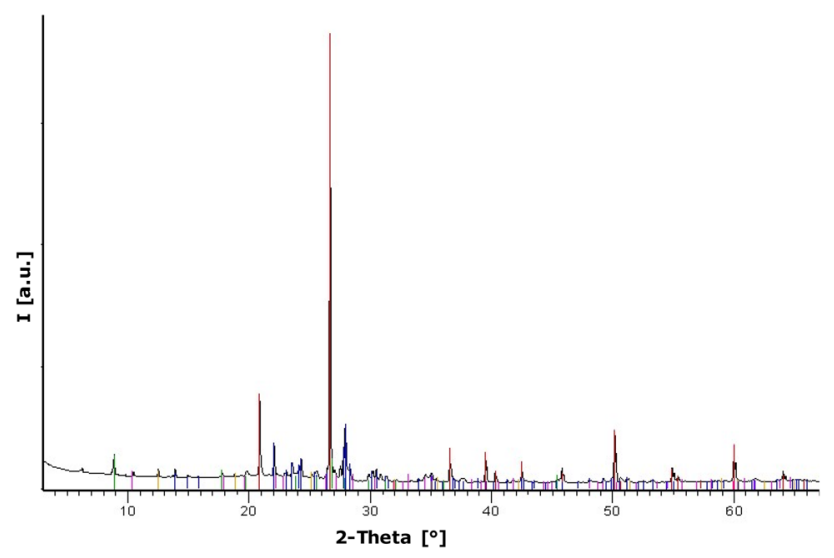

Fig. 1 XRD pattern of screened soil before soil washing. Theoretical peaks of identified phases are subtended: quartz in red, albite in blue, muscovite in green, chamosite in yellow and kaersutite in fuxia
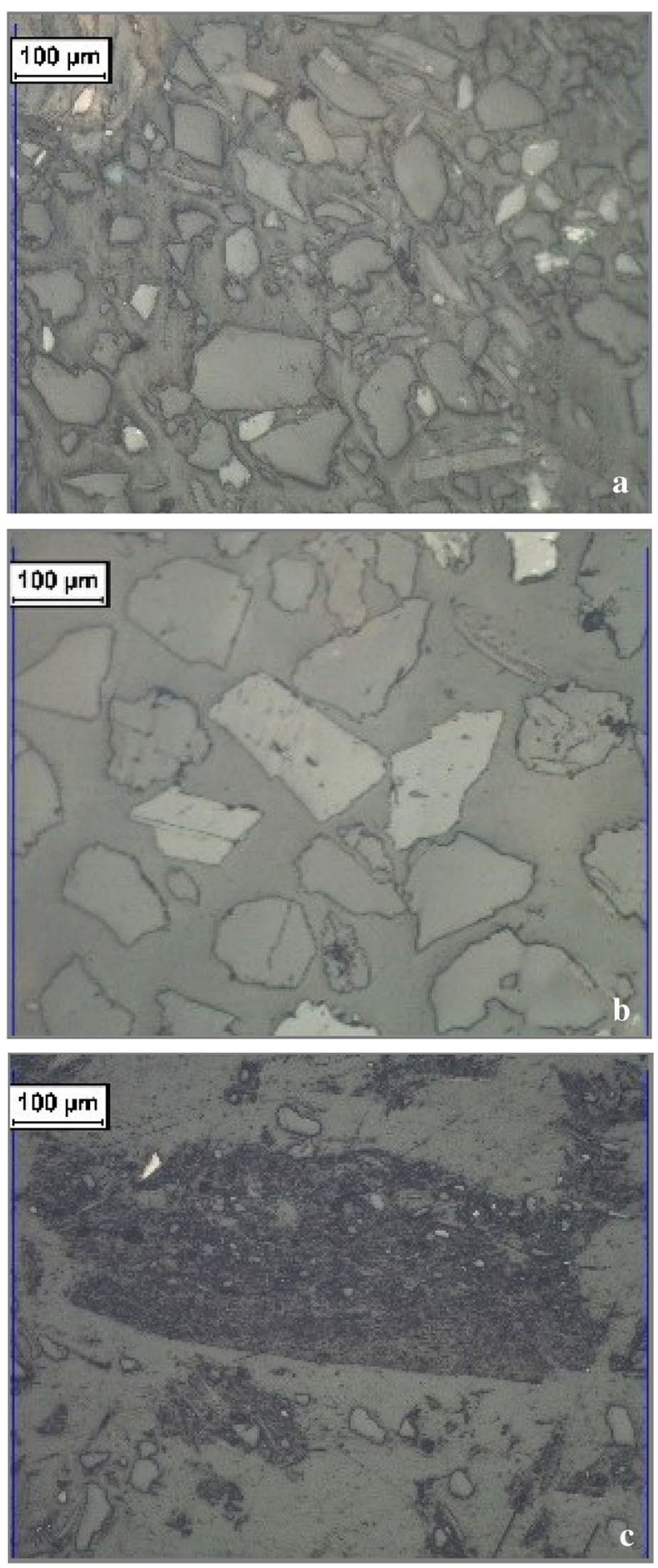

Fig. 2 Microscopic images of a screened soil before soil washing; b sand from soil recovered after soil washing; c silt from soil recovered after soil washing 
According to that, DDX contaminant mobilisation and their sorption on clays can be inferred as working microscopic phenomena involved in proposed soil washing treatment.

\section{Conclusion}

A soil washing treatment with sole water has been set up at laboratory scale, obtaining promising results on a contaminated soil with DDX level of $5050 \mathrm{mg} / \mathrm{kg}$. In particular, about $99 \mathrm{wt} \%$ of DDX contaminants has been concentrated in silt, representing only about $20 \mathrm{wt} \%$ of raw soil. According to that, it can be considered a possible step to DDX contaminated soil remediation and reuse. Economic benefits can be expected from drastic reduction in amount of DDX contaminated soil sent to disposal or further treatment. Indicatively, the following average Italian market costs can be traced: $0.98 \mathrm{k} €$ for each transport by truck of DDX contaminated soil (load of about $28 \mathrm{t}$; distance of $400 \mathrm{~km}) ; 0.80 \mathrm{k} € / \mathrm{t}$ for DDX contaminated soil incineration. DDX contaminant mobilisation and their sorption on clays present in silt can be inferred as working microscopic phenomena while any further hypothesis has to be considered too speculative at actual level of definition. Further clues could come from a deeper soil physical-chemical characterisation, especially in terms of chemical species potentially acting as co-solvents or surfactants.

Author contributions All authors contributed to the study. Data collection and analysis were performed by Manuela Grande, Sara Perucchini, Michela Bellettato and Erica Montanari. The first draft of the manuscript was written by Marco Tagliabue. All authors contributed to revision and approved the final version.

\section{Compliance with ethical standards}

Conflict of interest All authors are employees of Eni S.p.A. Marco Tagliabue is one of the inventors of a relevant patent application [16].

\section{References}

1. Binelli A, Provini D (2003) DDT is still a problem in developed countries: the heavy pollution of Lake Maggiore. Chemosphere 52:717-723. https://doi.org/10.1016/S0045-6535(03)00188-7

2. Ullah S, Faiz P, Aamir M, Sabir MA, Mahmood Q (2019) Occurrence and spatio-vertical distribution of DDT in soils of abandoned DDT factory area, Amangarh, Pakistan. SN Appl Sci 1:817. https://doi. org/10.1007/s42452-019-0830-8

3. Alavanja MCR, Ross MK, Bonner MR (2013) Increased cancer burden among pesticide applicators and others due to pesticide exposure. CA Cancer J Clin 63:120-142. https://doi.org/10.3322/ caac. 21170

4. Aislabie JM, Richards NK, Boul HL (1997) Microbial degradation of DDT and its residues: a review. NZ J Agric Res 40:269-282. https:// doi.org/10.1080/00288233.1997.9513247

SN Applied Sciences
5. Koustas RN, Fischer D (1998) Review of separation technologies for treating pesticide contaminated soil. J Air Waste Manage Assoc 48(5):434-440. https://doi.org/10.1080/10962247.1997.11877501

6. Morillo E, Villaverde J (2017) Advanced technologies for the remediation of pesticide contaminated soils. Sci Total Environ 586:576597. https://doi.org/10.1016/j.scitotenv.2017.02.020

7. Bayley RW, Biggs CA (2005) Characterisation of an attrition scrubber for the removal of high molecular weight contaminants in sand. Chem Eng J 111:71-79. https://doi.org/10.1016/j. cej.2005.05.009

8. Dermon G, Bergeron M, Mercier G, Riche Laflèche M (2008) Soil washing for metal removal: a review of physical chemical technologies and field applications. J Hazard Mater 152:1-31. https:// doi.org/10.1016/j.jhazmat.2007.10.043

9. Bisone S, Mercier G, Blais JF (2013) Decontamination of metals and polycyclic aromatic hydrocarbons from slag polluted soil. Environ Technol 34(18):2633-2648. https://doi.org/10.1080/09593 330.2013.781231

10. Amposah NY, Wang J, Zhao L (2018) A review of life cycle greenhouse gas (GHG) emissions of commonly used ex-situ soil treatment technologies. J Cleaner Prod 186:514-525. https://doi. org/10.1016/j.jclepro.2018.03.164

11. Hyman M, Dupont RR (2001) Soil washing in groundwater and soil remediation: process design and cost estimating of proven technologies. ASCE Press, Reston, pp 427-459

12. Feng D, Lorenzen L, Aldrich C, Maré PW (2001) Ex situ diesel contaminated soil washing with mechanical methods. Miner Eng 14(9):1093-1100. https://doi.org/10.1016/S0892-6875(01)00114 $-5$

13. Marino MA, Brica PM, Neale CN (1997) Heavy metal soil remediation: the effects of attrition scrubbing on a wet gravity concentration process. Environ Prog 16(3):208-214. https://doi.org/10.1002/ ep.3300160318

14. Neesse $T$, Schaaf $F$, Tiefel $H$ (2004) High performance attrition in stirred mills. Miner Eng 17:1163-1167. https://doi.org/10.1016/j. mineng.2004.06.026

15. Strazisar J, Seselj A (1999) Attrition as a process of comminution and separation. Powder Technol 105:205-209. https://doi. org/10.1016/S0032-5910(99)00139-4

16. Bagatin R, Careddu G, Tagliabue M (2017) Process for treating soils contaminated by organic non-hydrocarbon water insoluble pollutants. World Patent Application WO 2017/158547A1 by Syndial S.p.A.

17. Guemiza K, Coudert L, Tran LH, Metahni S, Blais JF, Besner S, Mercier $G$ (2017) Influence of soil parameters on the efficiency of the attrition process to remove metals, $\mathrm{PCP}$, dioxins and furans from contaminated soils. Water Air Soil Pollut 228:466. https://doi. org/10.1007/s11270-017-3633-9

18. EPA (2007) Method 3545A, Pressurised fluid extraction. EPA, Washington (DC). https://www.epa.gov/esam/method-3545a -sw-846-pressurized-fluid-extraction-pfe. Accessed 27 Feb 2019

19. EPA (2018) Method 8270D, Semi-volatile organic compounds by gas-chromatography mass-spectrometry. EPA, Washington (DC). https://www.epa.gov/hw-sw846/sw-846-test-method-8260d -volatile-organic-compounds-gas-chromatographymass-spect rometry. Accessed 27 Feb 2019.

20. Yuan GL, Quin JX, Li J, Lang XX, Wang GH (2014) Persistent organic pollutants in soil near the Changwengluozha Glacier of the central tibetan plateau, China: their sorption to clays and implication. Sci Total Environ 472:309-315. https://doi.org/10.1016/j.scito tenv.2013.11.061

Publisher's Note Springer Nature remains neutral with regard to jurisdictional claims in published maps and institutional affiliations. 